\title{
OLEB Executive Editors
}

\author{
Alan W. Schwartz
}

Published online: 14 September 2011

(C) Springer Science+Business Media B.V. 2011

With this issue, OLEB introduces a modified editorial structure. Two of our Editorial Board members, H.J. Cleaves and J. Peter Gogarten, will be assuming Executive Editor positions. Since its inception, Origins of Life has been a one-man operation, with, successively, Cyril Ponnamperuma, Jim Ferris, and myself as Editors. In today's world of increasing specialization, it is becoming increasingly difficult for one editor to be sufficiently familiar with the entire breath of the journal's coverage, or to easily identify and contact appropriate reviewers for every manuscript which is submitted. The new Executive Editors will act independently to stimulate, evaluate, and reach final decisions on new submissions within their areas of expertize. Jim Cleaves has a background in prebiotic chemistry, geochemistry and astrobiology. $\mathrm{He}$ is associated with the Geophysical Laboratory of the Carnegie Institution of Science, in Washington, D.C. Peter Gogarten is a specialist in Molecular and Early Biological Evolution, and is a Distinguished Professor in the Department of Molecular and Cell Biology at the University of Connecticut, Storrs, CT. I am delighted that I will be able to rely on their increased involvement in OLEB in the future.

A. W. Schwartz $(\bowtie)$

Radboud University Nijmegen, Nijmegen, The Netherlands e-mail: alan@sci.ru.nl 